\title{
Relative Contributions of Axonal and Somatic Na Channels to Action Potential Initiation in Cerebellar Purkinje Neurons
}

\author{
Zayd M. Khaliq and Indira M. Raman \\ Department of Neurobiology and Physiology and Institute for Neuroscience, Northwestern University, Evanston, Illinois 60208
}

\begin{abstract}
Neuronal excitability is likely to be regulated by the site of action potential initiation, the location on a neuron that crosses threshold first. Although initiation is axonal in many neurons, in Purkinje cells, somatic conductances can generate spontaneous action potentials, suggesting that the perisomatic region (soma and/or initial segment) contributes to spike initiation and may regulate firing. To identify directly the cellular regions at which Na channel modulation significantly influences firing, we measured spontaneous and evoked action potentials in Purkinje cells in cerebellar slices from postnatal day 14-28 mice while applying drugs locally to either the soma/initial segment or the first node of Ranvier. Na currents were decreased by tetrodotoxin (TTX) or increased by $\beta$-pompilidotoxin ( $\beta$-PMTX). Dual somatic and axonal recordings indicated that spike thresholds and input- output curves were sensitive to TTX or $\beta$-PMTX at the perisomatic region but were unchanged by either drug at the first node. When perisomatic Na channel availability was reduced with subsaturating TTX, however, the input- output curve became shallower during additional TTX block of nodal channels, revealing a latent role for nodal Na channels in facilitating firing. In perisomatic TTX, axons failed to generate spontaneous or evoked spike trains. In contrast, choline block of the initial segment alone altered normal input- output curves. The data suggest that, although the first node reliably follows action potentials, spike initiation in Purkinje neurons occurs in the initial segment. Moreover, Purkinje cell output depends on the density, availability, and kinetics of perisomatic Na channels, a characteristic that may distinguish spontaneously firing from quiescent neurons.
\end{abstract}

Key words: axon; initial segment; propagation; node of Ranvier; resurgent; Na current

\section{Introduction}

When a neuron fires, the membrane potential first crosses threshold at the initiation site, and the resulting action potential propagates to other regions of the cell. The responsiveness of a neuron to external stimuli, i.e., its input-output function, is therefore likely to be sensitive to any changes in the properties of the initiation site. In many cells, the initiation site is located in the axon, at or just beyond the initial segment (Coombs et al., 1957a,b; Moore and Westerfield, 1983; Moore et al., 1983; Colbert and Johnston, 1996; Colbert and Pan, 2002; Meeks et al., 2005). In cerebellar Purkinje neurons, direct recordings indicate that the axon hillock ( $7 \mu \mathrm{m}$ from the base of the cell body) depolarizes before the soma (Stuart and Häusser, 1994), and recent evidence has suggested that initiation occurs more distally, at the first node of Ranvier (Clark et al., 2005).

In acutely isolated preparations, however, in which somata usually retain $<10 \mu \mathrm{m}$ of axon (approximately one-third of the initial segment), Purkinje neurons from both rats and mice fire spontaneously (Nam and Hockberger, 1997; Raman and Bean,

Received Nov. 1, 2005; revised Jan. 3, 2006; accepted Jan. 3, 2006.

This work was supported by National Institutes of Health Grants NS047991 (Z.M.K.) and NS39395 (I.M.R.) and the Klingenstein Foundation (I.M.R.). We thank Sascha du Lac for the L7-GFP mice and Jason Pugh, Teresa Aman, Catherine Woolley, and Nelson Spruston for comments on a previous version of this manuscript. We are also grateful to Bernardo Sabatini for helpful discussion.

Correspondence should be addressed to Indira M. Raman, Department of Neurobiology and Physiology, 2205 Tech Drive, Northwestern University, Evanston, IL 60208. E-mail: i-raman@northwestern.edu.

DOI:10.1523/JNEUROSCI.4664-05.2006

Copyright $\odot 2006$ Society for Neuroscience $\quad$ 0270-6474/06/261935-10\$15.00/0
1999) at rates indistinguishable from those in slices (Häusser and Clark, 1997). Thus, at least under the extreme condition of axonal and dendritic cleavage, the perisomatic region (soma and initial segment) is capable of initiating spikes, raising the question of what the defining properties of an initiation site are, particularly in the special case of spontaneously firing neurons.

The ability of axons to initiate action potentials generally arises from their large net inward current relative to local capacitance, a trait achieved by a high $\mathrm{Na}$ channel density, low K channel density, relatively negative voltage of $\mathrm{Na}$ channel activation, and/or small membrane area (Coombs et al., 1957a,b; Moore and Westerfield, 1983; Moore et al., 1983; Stuart and Häusser, 1994; Colbert and Johnston, 1996; Colbert and Pan, 2002). With the exception of their large capacitance, Purkinje somata also satisfy these criteria. Somatic Na channel density is high (Stuart and Häusser, 1994; Raman and Bean, 1999), few K currents operate at subthreshold potentials (Raman and Bean, 1999; Southan and Robertson, 2000; Khaliq et al., 2003), and resurgent kinetics increase $\mathrm{Na}$ channel availability at interspike potentials (Raman and Bean, 1997, 2001). Whether Purkinje axons share these features is unknown, because direct recordings of axonal channels are still unfeasible.

On the premise that changing $\mathrm{Na}$ channel availability at the initiation site should influence neuronal excitability, we tested the roles of the soma, initial segment, and axon in spike initiation by pharmacologically modulating perisomatic or nodal Na currents of Purkinje neurons in cerebellar slices while measuring 
somatic and axonal action potentials. The gain of input-output curves and spike thresholds were highly sensitive to perisomatic but not nodal $\mathrm{Na}$ channel availability, whereas the distal axon reliably followed firing rates set by the perisomatic region. The results suggest that initiation occurs in the initial segment and that modulation of perisomatic $\mathrm{Na}$ channels changes firing rates, consistent with the active role of perisomatic conductances in generating spontaneous action potentials in Purkinje cells.

\section{Materials and Methods}

Slice preparation. Cerebellar slices were prepared from either C57BL/6 or L7-GFP (C57BL/6 background) (Sekirnjak et al., 2003) mice on postnatal day 15 (P15) to P29 (mean of P21). When noted, experiments were done on Wistar rats, aged P36-P39. In accordance with institutional guidelines, animals were anesthetized with halothane and transcardially perfused with ice-cold $\left(<4^{\circ} \mathrm{C}\right.$ ) artificial CSF (ACSF) (in mm: $123.75 \mathrm{NaCl}$, $3.5 \mathrm{KCl}, 26 \mathrm{NaHCO}_{3}, 1.25 \mathrm{NaH}_{2} \mathrm{PO}_{4}$, and 10 glucose) bubbled with $95 \%$ $\mathrm{O}_{2} / 5 \% \mathrm{CO}_{2}$. After decapitation, cerebella were removed, and parasagittal slices $(200 \mu \mathrm{m})$ were cut from the vermis on a vibratome (VT100S; Leica, Nussloch, Germany). Slices recovered for $\geq 1 \mathrm{~h}$ at $34^{\circ} \mathrm{C}$ in oxygenated ACSF. Recordings were made within $6 \mathrm{~h}$ of incubation. Except as noted, drugs were from Sigma (St. Louis, MO)

Electrophysiology. Slices were perfused at 3-4 $\mathrm{ml} / \mathrm{min}$ with oxygenated $\operatorname{ACSF}\left(33 \pm 1^{\circ} \mathrm{C}\right)$ with $10 \mu \mathrm{M}$ SR95531 [2-(3-carboxypropyl)-3-amino6-(4-methoxyphenyl)pyridazinium bromide], $10 \mu \mathrm{M}$ CPP [D(-)-3-(2carboxypiperazine-4-yl)-propyl-1-phosphonic acid], and $5 \mu \mathrm{m}$ DNQX (Tocris Cookson, Ellsville, MO) to block $\mathrm{GABA}_{\mathrm{A}}, \mathrm{NMDA}$, and AMPA receptors. Cells were visualized on an Axioskop FS2 (Zeiss) with infrared differential interference contrast (IR-DIC) (C2400; Hamamatsu, Bridgewater, NJ). Fast green was visualized with contrast enhancement under visible light. Somatic whole-cell recordings were made with borosilicate patch pipettes (3-4 M 2 ; A-M Systems, Carlsborg, WA). The intracellular solution contained $120 \mathrm{~mm} \mathrm{KCH}_{3} \mathrm{SO}_{3}, 10 \mathrm{~mm} \mathrm{NaCl}, 10 \mathrm{~mm}$ HEPES, 2 mм $\mathrm{MgCl}_{2}, 1$ mм EGTA, 0.066 mm Alexa Fluor 594 (Invitrogen, Carlsbad, CA), and $0.3-4 \%$ biocytin, buffered with $\mathrm{KOH}$ to $\mathrm{pH} 7.35$. Somatic recordings were made with an Axoclamp-2B amplifier in bridge mode, acquired at $50 \mathrm{kHz}$, and filtered at $10 \mathrm{kHz}$ with pClamp 8.2 software (Molecular Devices, Palo Alto, CA). Capacitance was compensated and the bridge was balanced. Cells with series resistances $>20 \mathrm{M} \Omega$ were discarded.

For axonal recordings (Khaliq and Raman, 2005), somatic whole-cell recordings were first established in cells in which the axon could be identified for $>50 \mu \mathrm{m}$ with IR-DIC. After allowing a cell to fill with Alexa Fluor 594 ( $\sim 15 \mathrm{~min})$, the axonal recording location was generally selected under fluorescence from a monochronometer (T.I.L.L. Photonics, Gräfelfing, Germany) to confirm the identity of the axon in the corticonuclear tract. To limit phototoxicity, fluorescence was flashed at $\sim 3 \mathrm{~Hz}$ ( $150 \mathrm{~ms}$ pulses) and constrained to a $50 \times 50 \mu \mathrm{m}$ square. Some recordings were obtained with only IR-DIC. A loose patch seal onto the myelin at the selected axonal site was made with a patch pipette (5-7 M $\Omega$ ) filled with $145 \mathrm{~mm} \mathrm{NaCl}$ and $10 \mathrm{~mm}$ HEPES, buffered with $\mathrm{NaOH}$ to a $\mathrm{pH}$ of 7.4. Axonal signals were acquired with an Axopatch 200B amplifier in current-clamp mode, sampled at $50 \mathrm{kHz}$, and filtered at $5 \mathrm{kHz}$.

To generate input-output curves, a tonic hyperpolarizing current was injected to hold cells near $-70 \mathrm{mV}$, and a series of $400 \mathrm{~ms}$ current steps was injected into the cell, starting at $-0.3 \mathrm{nA}$ and incrementing by $0.1 \mathrm{nA}$. For suprathreshold current injections, Purkinje cells nearly always responded by firing a regular train of action potentials that lasted throughout the step, from which the firing rate could be calculated as spikes per second. Exceptions included irregular trains at low current injections, occasional bursts, and depolarization block at the highest current injections. Current amplitudes were increased until the cell entered depolarization block and ceased to fire throughout the step. The maximal firing rate was taken as the spike rate evoked by the previous step.

For local drug application, patch pipettes $(3-5 \mathrm{M} \Omega$ ) were filled with tetrodotoxin (TTX) (Alomone Labs, Jerusalem, Israel) or $\beta$-pompilidotoxin ( $\beta$-PMTX) (5-10 $\mu \mathrm{M}$; Tocris Cookson) dissolved in HEPES-buffered ACSF ("puffer ACSF") containing the following (in $\mathrm{mm}$ ): $150 \mathrm{NaCl}, 3.5 \mathrm{KCl}, 10 \mathrm{HEPES}, 1 \mathrm{MgCl}_{2}$, and $2 \mathrm{CaCl}_{2}$, buffered to $\mathrm{pH}$ 7.35 with $\mathrm{NaOH}$. Except as noted, TTX was used at $100 \mathrm{nM}$, a concentration that is $\sim 30$ times the $K_{\mathrm{d}}$ under conditions of ideal access of the drug to channels (Raman and Bean, 1997; Swensen and Bean, 2005). This concentration was chosen to be high enough to provide a substantial block in slices but low enough to keep the effects localized to the desired region of the neuron. For nodal application, the puffer pipette tip was positioned over the first branch point (within $5 \mu \mathrm{m}$ ) and visualized under fluorescence, and the solution was delivered by applying continuous pressure to the pipette through a syringe. During application, a small radius $(5-10 \mu \mathrm{m})$ of tissue displacement was detectable. Positive controls in which TTX successfully blocked a substantial fraction of Na channels at the node include detection of propagation failures and effects of nodal TTX with perisomatic subsaturating TTX (sub-TTX) (see Results).

For local perfusion of the initial segment, choline- $\mathrm{Cl}$ was substituted for $\mathrm{NaCl}$, and $0.5 \%$ fast green was included in the puffer ACSF. After the proximal axon was visualized under fluorescence, the puffer pipette tip was positioned $\sim 10 \mu \mathrm{m}$ from the soma, at the midpoint of the initial segment (Gianola and Rossi, 2004). Light microscopy with contrast enhancement was used to visualize the application area as solution was applied. To ensure that choline was restricted to the initial segment, normal puffer ACSF was simultaneously applied to the soma with a second puffer pipette. Images were captured during current-clamp recordings with a Videum video card (Winnov, Santa Clara, CA).

Data and statistical analysis. Analysis was done in Igor Pro (WaveMetrics, Lake Oswego, OR). Axonal traces were analyzed to identify propagation successes and failures (Khaliq and Raman, 2005). Axonal signals were considered successes if the largest peak-to-peak voltage deflection (maximal peak-to-peak separation, $0.8 \mathrm{~ms}$ ) within a $1.2 \mathrm{~ms}$ window about the peak of a somatic action potential exceeded 3 SDs above the noise. The mean noise amplitude was estimated by averaging 300 axonal peak-to-peak measurements taken in the absence of somatic spikes ( $>1.3 \mathrm{~ms}$ from a somatic spike). Latencies were measured as the time of the maximal $d V / d t$ of the somatic spike subtracted from the time of the peak of the corresponding axonal spike (Meeks et al., 2005). Threshold was estimated as $2 \%$ of the maximal $d V / d t$ (Jackson et al., 2004). The presence of the first depolarizing phase in the somatic spike $d V / d t$ was confirmed by a corresponding region of negative slope in the second derivative.

Data are reported as mean \pm SE. Maximal slopes in input-output curves were measured by linear regression over more than three points in the steepest portion of the curve. Statistical significance was assessed with Student's paired two-tailed $t$ tests, unless noted in the text as unpaired. Single asterisks in figures indicate $p<0.05$; double asterisks indicate $p<$ 0.001 .

Histology. Slices with biocytin-filled cells were transferred to $4 \%$ paraformaldehyde and stored at $4^{\circ} \mathrm{C}$ for $>24 \mathrm{~h}$. Slices were rinsed in PBS, and endogenous peroxidases were quenched by rinsing in $3 \% \mathrm{H}_{2} \mathrm{O}_{2}$ and $10 \%$ methanol in PBS for $30 \mathrm{~min}$. Slices were permeabilized with $2 \%$ Triton X-100 (Sigma) in PBS for $1 \mathrm{~h}$ and treated with ABC Vectastain Kit (Elite PK-6100; Vector Laboratories, Burlingame, CA) for $2 \mathrm{~h}$. After rinsing in PBS, slices were DAB stained (Sigma Fast kit), rinsed again, and mounted for viewing. Images were recorded with a CCD camera (Optronics, Chelmsford, MA), and axon lengths were measured with Neurolucida software.

\section{Results}

With a goal of identifying regions on the Purkinje cell in which modulation of $\mathrm{Na}$ channels would have measurable, significant effects on firing rate, we applied blockers or modulators of $\mathrm{Na}$ channels to the soma and initial segment (the perisomatic region) and/or the first node of Ranvier and monitored the effects on spontaneous and evoked action potentials. First, to test the contribution of $\mathrm{Na}$ channels in the first node to Purkinje cell firing, somatic action potentials were recorded under current clamp while TTX was applied locally ( $\sim 30 \mu \mathrm{m}$ diameter region) to the first branch point of the axon, which corresponds to the first node (Gianola and Rossi, 2004; Clark et al., 2005). To facilitate visual- 
ization of the axon, Alexa Fluor $594(66 \mu \mathrm{M})$ was included in the somatic whole-cell recording pipette, and a puffer pipette was positioned at the first branch point (Fig. $1 \mathrm{~A}$ ), which was $138 \pm 6$ $\mu \mathrm{m}$ from the base of the soma $(n=44)$. As a first step in validating this approach, we first confirmed that the puffer pipette solution could reach axonal channels by applying $140 \mathrm{mM} \mathrm{K}^{+}$to the first node and measuring responses in somata held at -70 or -60 $\mathrm{mV}$. Consistent with successful perfusion of the node, $140 \mathrm{~K}^{+}$ elicited a depolarization from $-70 \mathrm{mV}$ and evoked trains of action potentials from $-60 \mathrm{mV}(n=6)$ (Fig. $1 B)$. Lateral movement of the pipette along the myelin, either $\sim 20 \mu \mathrm{m}$ toward or away from the soma, eliminated the somatic depolarization, supporting the idea that the effect of perfusion was localized to the node.

Next, in physiological $\mathrm{Na}^{+}$and $\mathrm{K}^{+}, 100 \mathrm{~nm}$ TTX was applied to the first node. Nodal TTX did not change the action potential waveforms (Fig. 1C). The rate of firing, measured either with no injected current or on release of negative holding current, also remained unchanged $(n=15 ; p=0.52)$ (Fig. $1 D)$. To test the effect of blocking nodal $\mathrm{Na}$ channels on evoked action potentials, cells were silenced by hyperpolarization to $-70 \mathrm{mV}$, and inputoutput curves were generated with somatic current steps. On average, neither input-output curves nor thresholds were changed by nodal TTX. The maximal firing rate of $290 \pm 9$ spikes/s in control remained at $284 \pm 11$ spikes/s with nodal TTX $(n=16 ; p=0.34)$ (Fig. $1 E)$, and threshold was $-51 \pm 1 \mathrm{mV}$ in both conditions $(n=16 ; p=0.99)$ (Fig. $1 F)$. Similar results were obtained in Purkinje cells in slices from rat cerebellum $(n=3)$ (supplemental Fig. 1, available at www.jneurosci.org as supplemental material). After each experiment, the TTX pipette was moved near the soma to test whether TTX was flowing from the pipette. With application of perisomatic TTX, repetitive firing was abolished $(n=18)$ (Fig. $1 E)$. These results suggest that $\mathrm{Na}$ channels in the first node of Purkinje axons are not necessary for maintaining the normal rate or threshold of somatic spikes.

It is possible, however, that distal regions of the axon assume the role of the first node during nodal TTX application or that TTX failed to reach nodal channels at a sufficiently high concentration to block them. Therefore, as an alternative method to estimate the relative contribution of the whole axon to firing, we compared action potentials in cells that lacked axons with those of cells that retained them (Colbert and Pan, 2002). Cells were considered to have "no axon" only if their axon had been cut (during normal preparation of slices) within $30 \mu \mathrm{m}$ from the soma, as detected with fluorescence. To minimize the variance of population responses, comparisons were made between axonretaining and axon-free cells in the same sets of slices. Spontaneous and maximal firing rates did not differ in cells with axons (90 \pm 6 and $305 \pm 12$ spikes/s) and without axons (99 \pm 11 and $288 \pm 18$ spikes $/ \mathrm{s} ; n=9$ per group; $p=0.49, p=0.44$, unpaired), nor was threshold significantly different $(-47.3 \pm 1$ vs $-45.5 \pm$ $1 \mathrm{mV} ; p=0.22$, unpaired) (Fig. $1 G, H)$. These results provide additional support to the idea that, in normal physiological saline, the perisomatic region alone is sufficient to initiate action potentials, whereas the first node makes little contribution to the generation of normal firing patterns.

It seems likely, however, that $\mathrm{Na}$ channels at the first node influence the propagation of action potentials to more distal points on the axon. To measure the effect of nodal TTX on action potential propagation, we made simultaneous somatic and axonal recordings (Khaliq and Raman, 2005). During somatic whole-cell current-clamp recordings, loose-patch recordings were made from axons $25-422 \mu \mathrm{m}$ distal to the first node.
Under control conditions, propagation was $>90 \%$ reliable up to $\sim 230$ spikes/s $(n=6)$ (Fig. 2A,C) (Khaliq and Raman, 2005). Application of nodal TTX reduced the efficiency of propagation, so that the percentage of successes fell below $90 \%$ at a lower firing rate ( $\sim 150$ spikes/s) (Fig. $2 B, C)$. Although not surprising, this result provides a useful positive control indicating that the puffed TTX was successful in reducing nodal $\mathrm{Na}$ channel availability. Higher concentrations of nodal TTX $(1 \mu \mathrm{M})$ further reduced the percentage of propagation; nevertheless, the somatic input-output relationship remained unchanged in high TTX, consistent with the results from $100 \mathrm{~nm}$ nodal TTX and cells with no axons. Additionally, the number of failures did not decrease with recording distance even $>400 \mu \mathrm{m}$ beyond the first node, suggesting that the absence of axonal signals corresponded to true propagation failures rather than action potentials with reduced amplitudes in the vicinity of the first node.

Because inferences about initiation site have been made on the basis of latency measurements (Clark et al., 2005), we tested whether nodal TTX changed spike latency. Nodal TTX increased the latency between somatic and distal axonal action potentials $(n=6 ; p<0.001)$ (Fig. 2D). This increased latency can be interpreted in at least two ways. Either the initiation site was indeed at the first node in control solutions, and TTX shifted initiation toward the soma, or the initiation site was originally perisomatic and remained so in nodal TTX, but blockade of nodal Na channels slowed conduction along the axon. As a first effort to distinguish between these possibilities, we compared the derivatives of somatic spikes corresponding to successful propagation in control solutions with those corresponding to failed propagation in nodal TTX (Fig. 2E). In control solution, the derivative of the waveform has two phases, which correspond in other preparations to the early depolarization in the axon followed by the later depolarization of the soma (Coombs et al., 1957a; Colbert and Johnston, 1996). In Purkinje cells, two phases are also detectable, although they blend, such that no region of negative slope exists between them. We reasoned that blockade of $\mathrm{Na}$ channels at the initiation site would necessarily change the early depolarization. As shown in Figure $2 F$ (top, middle), however, the somatic spikes as well as their derivatives with and without nodal TTX retained the first depolarizing phase, although the blockade of nodal $\mathrm{Na}$ channels was confirmed by the absence of a propagating spike $(n=7)$ (Fig. $2 F$, bottom). Together, these data are consistent with the idea that the first node primarily acts to increase the fidelity of propagation of high-frequency action potentials, which are initiated perisomatically.

Because $\mathrm{Na}$ channel density can be a major determinant of firing properties, it seemed possible that the perisomatic region might dominate Purkinje firing patterns because of its highamplitude $\mathrm{Na}$ currents. If so, firing may be more sensitive to nodal $\mathrm{Na}$ channel activity if the number of functional perisomatic $\mathrm{Na}$ channels is reduced. To test this possibility, we first recorded the change in input-output curves induced by perisomatic subTTX (3-10 nM) (Fig. 3A). As shown in Figure 3B, perisomatic sub-TTX decreased the amplitude and reduced the rate of rise of spontaneous action potentials. Additionally, sub-TTX raised rheobase for evoking spikes by $150 \pm 27 \mathrm{pA}(n=9 ; p<0.001)$, decreased the maximal slope of the input-output curve from $305 \pm 20$ to $258 \pm 16 \mathrm{~Hz} / \mathrm{nA}(p=0.05)$ (Fig. $3 C)$, and raised threshold by $1.7 \pm 1.1 \mathrm{mV}(p=0.04)$ (Fig. $3 B, D)$, consistent with an effective reduction in somatic Na channel availability by sub-TTX.

Next, during continued perfusion of the perisomatic region with sub-TTX, 100 nм TTX (referred to simply as "TTX”) was 
A
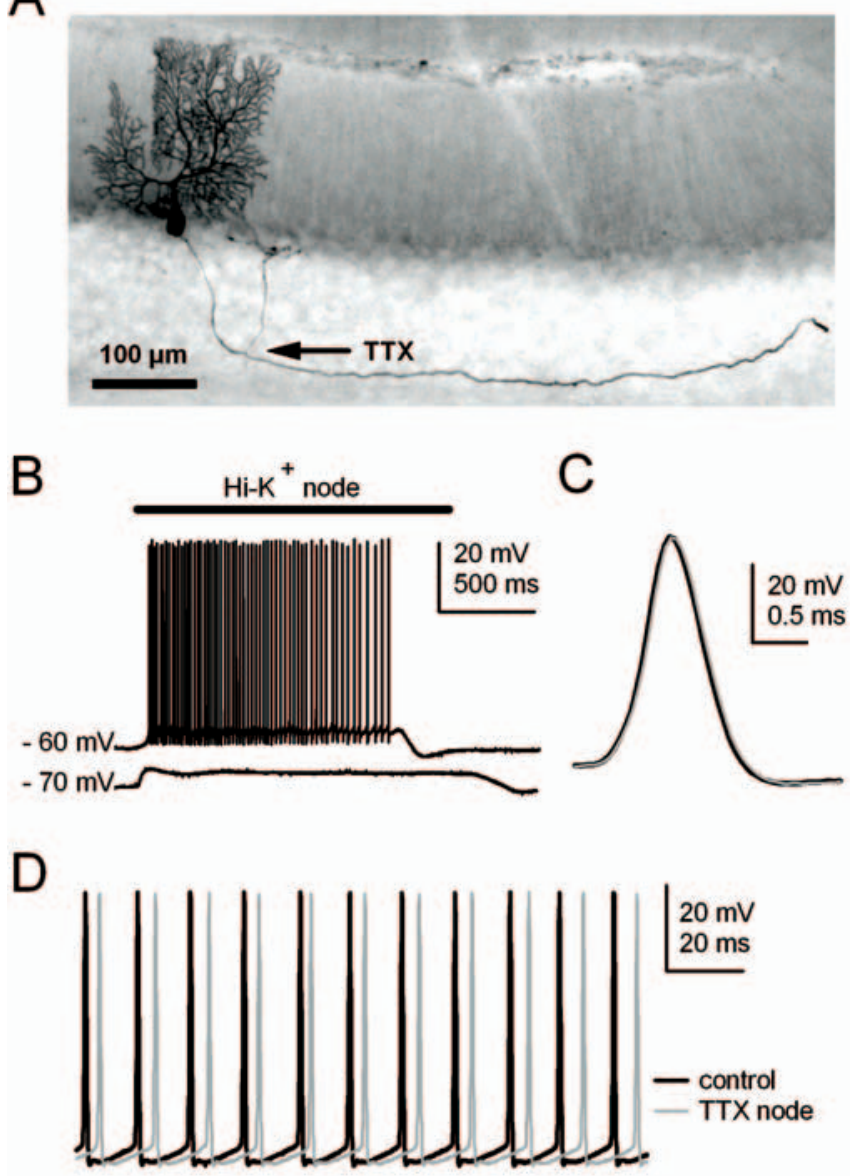

E

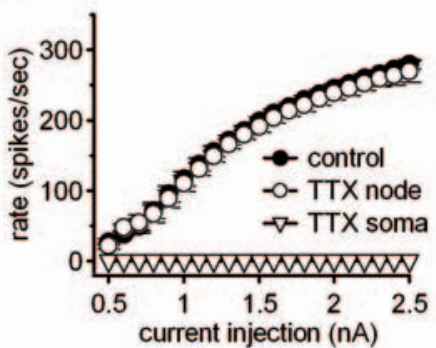

G

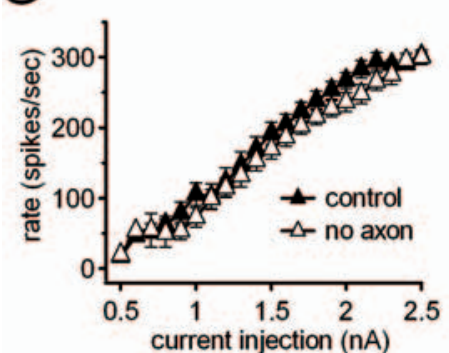

$\mathrm{F}$

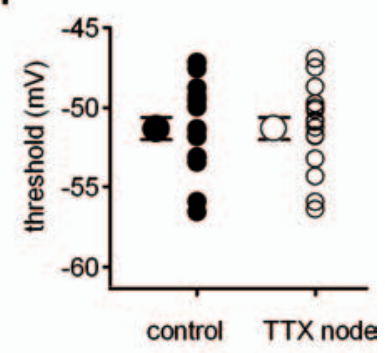

$\mathrm{H}$

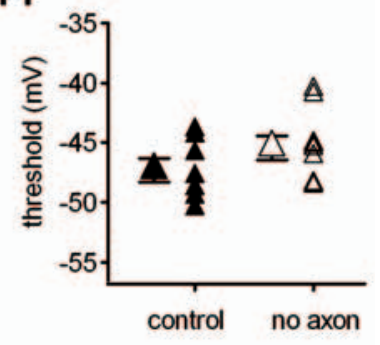

Figure 1. Action potentials during blockade of $\mathrm{Na}$ channels at the first node. $\boldsymbol{A}$, Purkinje cell stained with DAB. Arrow, Location of first branch point (first node) and site of TTX application (147 $\mu \mathrm{m}$ from soma). $\boldsymbol{B}$, Somatic response to $140 \mathrm{~mm} \mathrm{~K}^{+}$applied to first node (different cell from $A$ ), from holding at -60 or $-70 \mathrm{mV}$, as labeled. $C$, Overlay of a single spontaneous action potential in control (black trace) and with nodal TTX (gray trace; same cell as $\boldsymbol{A}$ ). $\boldsymbol{D}$, Longer records of spontaneous firing in control (73 spikes/s) and with nodal TTX (70 spikes/s; from same recording as $\boldsymbol{C}$. $\boldsymbol{E}$, Mean input- output curves, plotted as sustained firing rate versus current injections for control (filled circles), nodal TTX (open circles; paired recordings, $n=16$ ), and somatic TTX (open triangles; unpaired, $n=18$ ). $\boldsymbol{F}$, Threshold values in control and nodal TTX

applied to the first node $(n=9)$. Unlike nodal TTX alone, nodal TTX in the presence of perisomatic sub-TTX changed both the action potential waveform and firing rate (Fig. $3 B$ ). Moreover, rheobase increased by another $175 \pm 36 \mathrm{pA}(p<0.001$ vs subTTX and vs control), the maximal slope of the input-output relationship dropped to $221 \pm 28 \mathrm{~Hz} / \mathrm{nA}$ ( $p=0.07$ vs sub-TTX $p=0.007 \mathrm{vs} \mathrm{control}$ ) (Fig. $3 C$ ), and threshold further increased ( $p=0.04$ vs sub-TTX; $p<0.001$ vs control) (Fig. $3 B, D$ ). The cumulative effect of sub-TTX at the soma and TTX at the node was indistinguishable whether TTX application at the node preceded sub-TTX at the soma $(n=5)$ or followed it $(n=9)$. These data support the idea that it is the large number of perisomatic $\mathrm{Na}$ channels that normally make reductions in $\mathrm{Na}$ channel activity in the first node inconsequential. They also suggest that, under conditions of relatively low perisomatic $\mathrm{Na}$ channel availability, either experimentally induced or naturally occurring, nodal channels can facilitate action potential initiation. Additionally, as $\mathrm{Na}$ channel availability changes at either site, as it may with rapid firing or channel modulation, the axon and soma may change their relative contributions to action potential generation.

We therefore tested the effect of increasing perisomatic or axonal Na channel availability with $\beta$-PMTX, which destabilizes fast inactivated states of $\mathrm{Na}$ channels (Kinoshita et al., 2001). In classical $\mathrm{Na}$ channels, the reduction of fast inactivation increases persistent current, whereas in Na channels with resurgent kinetics, it enlarges resurgent current (Grieco and Raman, 2004). In both cases, the increased depolarizing drive is likely to promote action potential generation. Consistent with this prediction, perisomatic application of $\beta$-PMTX increased the firing rate evoked by any given current injection (Fig. $4 \mathrm{~A}$ ) and decreased threshold $(n=10 ; p<0.002)$ (Fig. 4C,G). Most importantly, the maximal slope of the input-output curve increased (from $252 \pm 23$ to $376 \pm 47 \mathrm{~Hz} / \mathrm{nA} ; n=16 ; p=0.005)$, while leaving the maximal firing rate unchanged $(290 \pm 10$ vs. $293 \pm 15$ spikes $/$ s; $n=16 ; p=$ 0.76) (Fig. 4E). These results indicate that the additional $\beta$-PMTX-induced Na current did more than contribute subthreshold depolarization, which would be expected simply to left-shift the input-output curve. Instead, it increased the gain of the curve, suggesting that, for any given stimulus, the availability of perisomatic $\mathrm{Na}$ channels sets the rate at which spike initiation can occur.

In contrast, when $\beta$-PMTX was applied to the first node, the action potential waveforms, input-output curves, and threshold remained unchanged ( $n=7$ ) (Fig. $4 B, D, F, G)$. Because all of the $\mathrm{Na}$ channel $\alpha$ subunits that are expressed by Purkinje neurons are sensitive to $\beta$-PMTX (Kinoshita et al., 2001; Grieco and Raman, 2004), it is unlikely that axonal Na channels were not modulated by the toxin. Instead, these results suggest that even increasing nodal $\mathrm{Na}$ channel availability and/or opening cannot override the firing rate set by perisomatic channels.

The observation that high-frequency action potentials fail to propagate if the excitability of first node is reduced by TTX raises the question of whether propagation will also fail when the excitability of the perisomatic region is elevated by $\beta$-PMTX. Specifically, if the nodal channels, untreated by $\beta$-PMTX, can set an upper limit on firing rate evoked by a given stimulus, then propagation reliability should decrease. Therefore, to test the reliabil-

$\leftarrow$

( $n=16$; small symbols, individual values; large symbols, mean). $\mathbf{G}$, Input- output curves for cells with (filled symbols) and without (open symbols) axons ( $n=9$, each group). $\boldsymbol{H}$, Threshold values for cells in $\mathbf{G}$. 
A
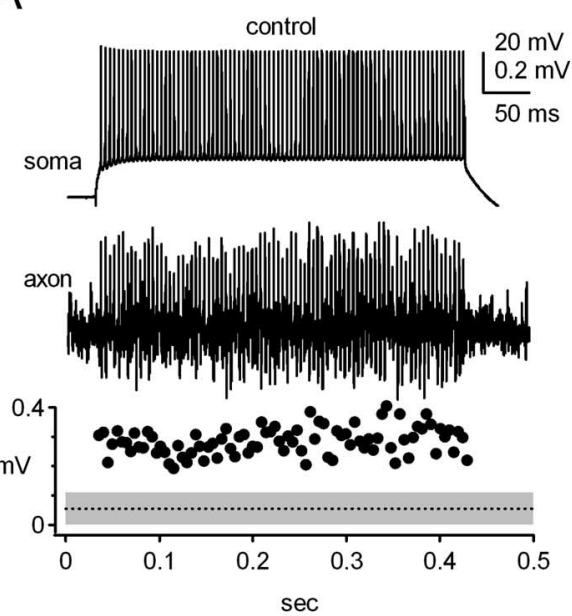

C

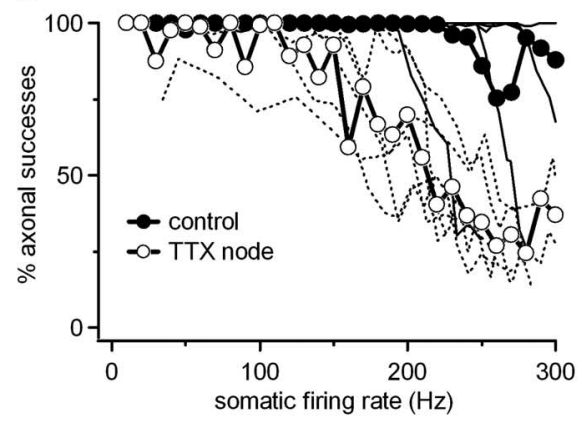

E

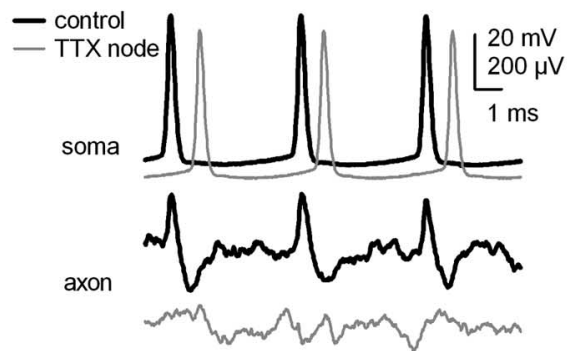

B
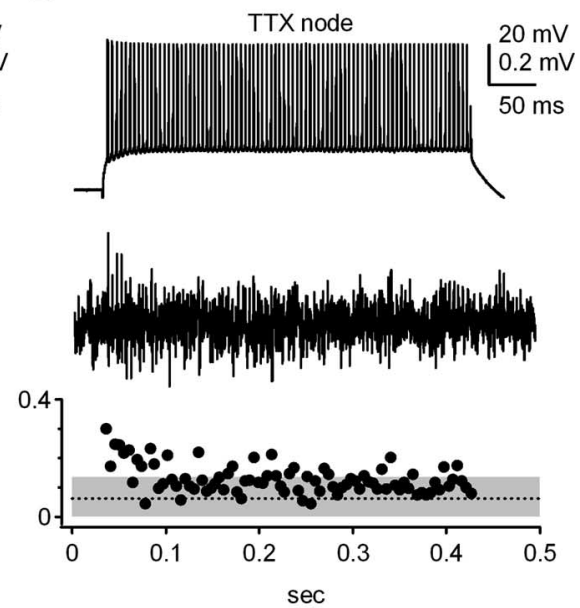

D

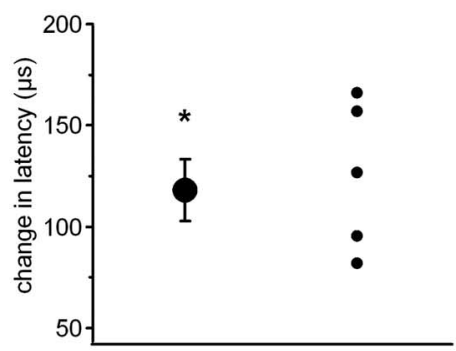

$\mathrm{F}$

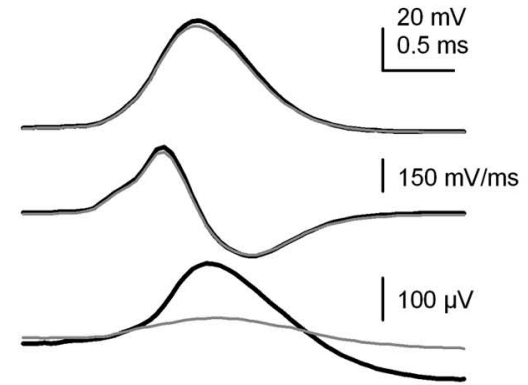

Figure 2. Dual recordings of somatic and axonal action potentials. $\boldsymbol{A}, \boldsymbol{B}$, Somatic (top) and axonal (middle) action potentials, with plots (bottom) of the amplitudes of axonal signals (circles) and noise (mean, dotted line; \pm 3 SDs, gray shading) in control $(\boldsymbol{A})$ and with TTX on first node $(\boldsymbol{B})$. Axonal recording electrode, $218 \mu \mathrm{m}$ from the base of the soma. Spikes were evoked by current steps from $-70 \mathrm{mV}$. Control, Somatic firing rate, 211 spikes/s; successful propagation, 100\%. Nodal TTX, Somatic firing rate, 213 spikes/s; successful propagation, 35\%. C, Percentage of propagation successes versus firing rate for control and nodal TTX (as labeled) for mean (symbols) and individual (lines) data $(n=6)$. $\boldsymbol{D}$, Change in latency between somatic and axonal spikes during application of nodal TTX. Large symbol, Mean; small symbols, individual values. $\boldsymbol{E}$, Expanded representative somatic and axonal spikes from $\boldsymbol{A}$ and $\boldsymbol{B}$. Control (black) and nodal TTX (gray); somatic and axonal records are time locked. $\boldsymbol{F}$, Somatic spikes (top), derivatives of the somatic waveform ( $d V / d t$; middle), and axonal waveforms (bottom). Control, Black; nodal TTX, gray. Traces are averages of spikes during second half of current step in $\boldsymbol{B}$.

ity of propagation during somatic $\beta$-PMTX, we made simultaneous somatic and axonal recordings. As illustrated in Figure 5, $A$ and $B$, and summarized in Figure $5 C$, although fixed current injections evoked higher spike rates in perisomatic $\beta$-PMTX than in control solutions, propagation was equally successful with and without the toxin $(n=6)$. These results indicate that any transmitter or drug-induced modulation that increases the availability of perisomatic $\mathrm{Na}$ channels alone is sufficient to increase the firing rate in Purkinje axons.

These data are consistent with the classical notion of the first node and distal axon as followers of perisomatic activity. They do not, however, rule out the possibility that either spontaneous or evoked action potentials might occur without excitation from the perisomatic region, i.e., that conditions may exist in which the axon can act as the driver rather than the follower. To test the ability of the first node and distal axon to initiate spikes in the absence of input from the soma and/or initial segment, simultaneous recordings of somatic and distal axonal activity were made while $100 \mathrm{~nm}$ TTX was applied perisomatically. Perisomatic TTX silenced spontaneous firing in both the somatic and axonal traces $(n=8)$ (Fig. $6 A$ ). Next, we tried to generate action potentials by depolarizing the axon via somatic current injections. The largest currents (1.5$4.5 \mathrm{nA}$ ) elicited only one to three spikes at the beginning of the $400 \mathrm{~ms}$ step $(n=8)$ (Fig. 6B,C), after which spiking ceased, indicating that the first node and distal axon were unable to sustain trains of action potentials with perisomatic $\mathrm{Na}$ channels blocked. Interestingly, however, the lowamplitude somatic spike in TTX could not have arisen from the soma or initial segment and may instead have originated in either the most distal initial segment or the first node, because Purkinje dendrites do not tend to produce fast Na-dependent spikes (Llinás and Sugimori, 1980). Consistent with the idea that perisomatic TTX forced the initiation site to move to a more distal site in the axon, the latency between the action potential in the soma and in the distal axon decreased in perisomatic TTX $(n=8 ; p=0.025)$ (Fig. $6 D)$.

Given the accumulation of evidence for a perisomatic initiation site, we next tested whether a role for the initial segment could be distinguished from that of the soma by blocking $\mathrm{Na}$ channels in the initial segment with a choline-substituted ACSF while puffing normal ACSF over the cell body. The location of the Na channel block was monitored with fast green included in the choline solution and was restricted to the first $20-40 \mu \mathrm{m}$ of the axon (Fig. $7 A$ ). Two cells are included to illustrate the extent of choline perfusion and the reliability of the effect. As shown in Figure 7, $B$ and $C$, choline slowed firing rates without affecting responses to subthreshold current steps. Similar results were obtained in two more cells with axons that were intact beyond the first node, as well as two cells with axons cut at $\sim 10 \mu \mathrm{m}$. When choline application extended over more than half the soma, cells stopped firing trains of fast action potentials in response to current steps, and the largest injections produced broad, low-amplitude action potentials that resembled calcium spikes ( $n=4$; data not shown). Differentiating the action potential waveforms revealed that choline perfusion over the initial segment reduced the initial inflec- 
A
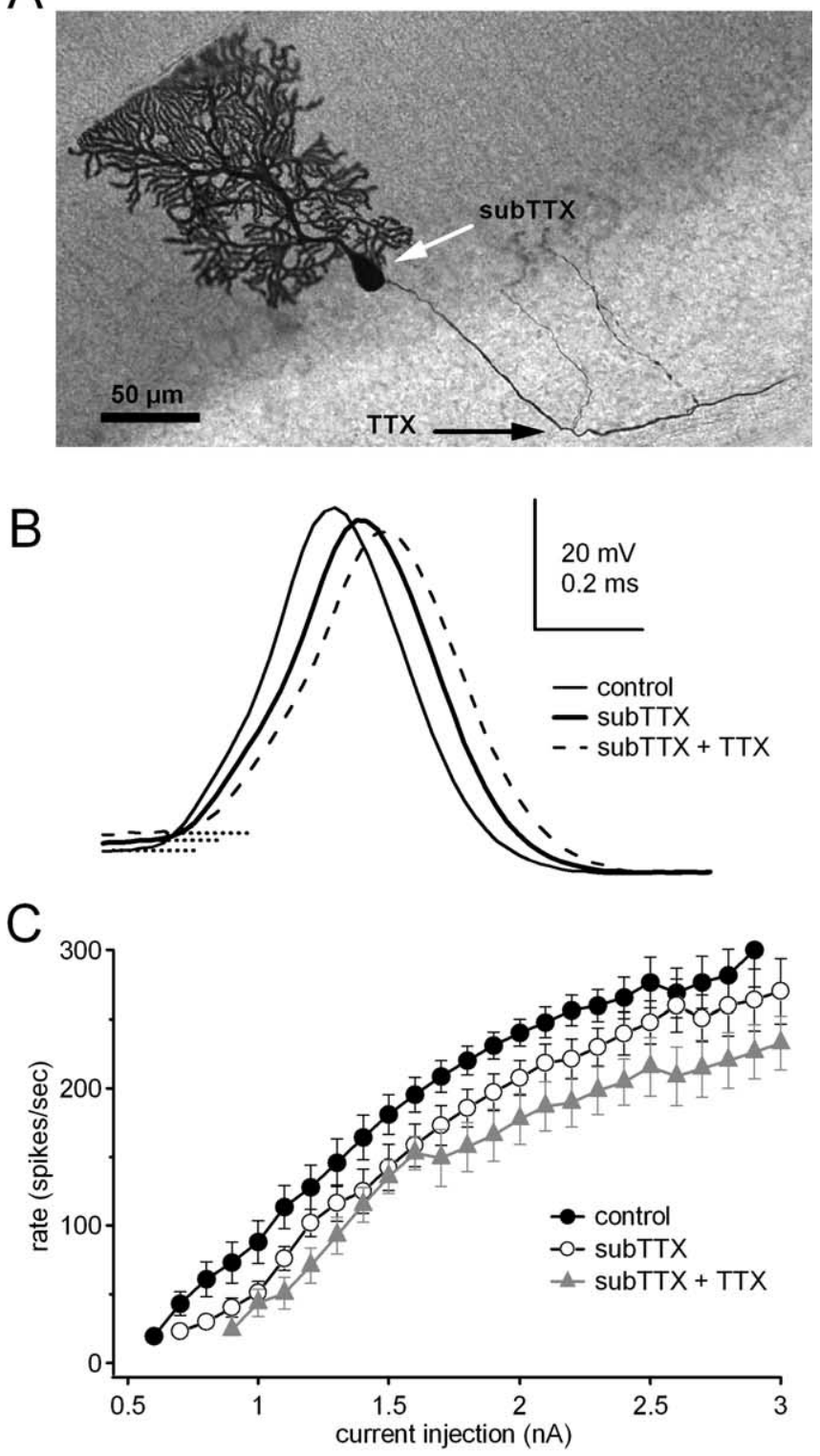

D

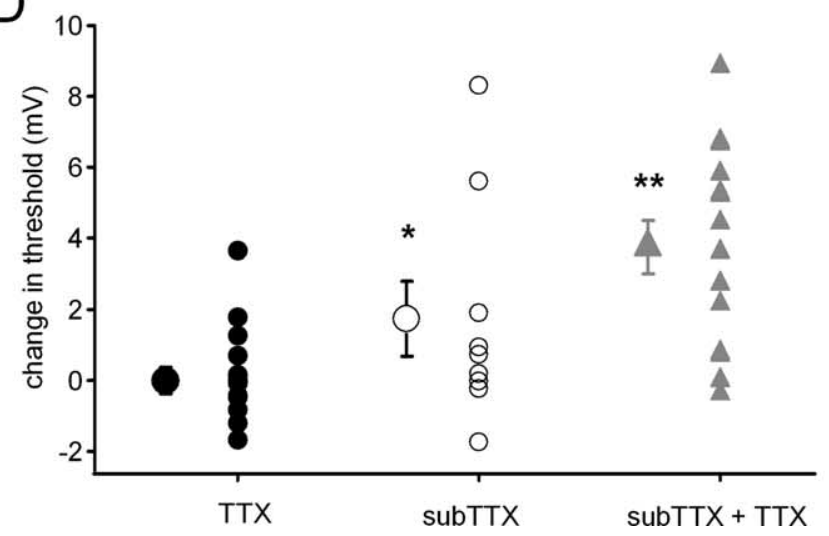

Figure 3. Combined effects of subsaturating $\Pi X$ at the soma and saturating $\Pi X$ at the first node. $A$, Purkinje cell. White arrow, Application site for subsaturating $\Pi X$; black arrow, application site of saturating TXX (firstnode, $155 \mu$ mfrom soma). $\boldsymbol{B}$, Overlay of spike waveforms, evoked from $-70 \mathrm{mV}$, offsetfor clarity. Dotted lines, Thresholds for spikes in control (thin line, $-48 \mathrm{mV}$ ), somatic sub- $\Pi \mathrm{XX}$ (thickline, $-44 \mathrm{mV}$ ), and somatic sub-TX plus nodal ITX (dashed line, $-38 \mathrm{mV}$ ). C, Input- output curves for the three conditions, as labeled $(n=9)$. $\boldsymbol{D}$, Change inthreshold relativeto control withnodal $\operatorname{TX}(n=16)$, somaticsub- $\operatorname{TX}(n=9)$, and both $(n=14)$. Asterisks, Unpaired comparisons.
A

B
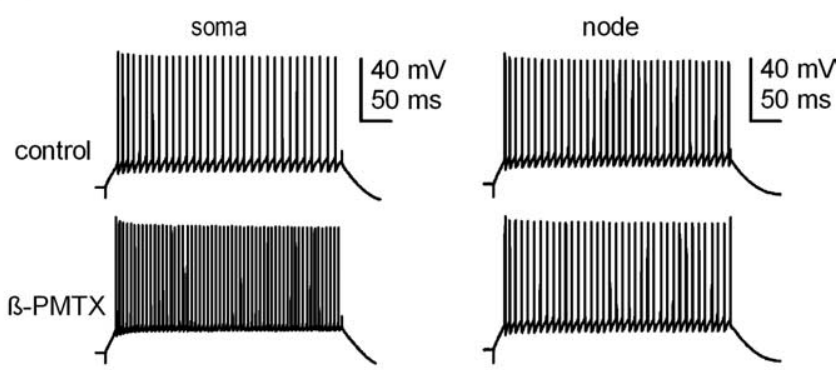

C
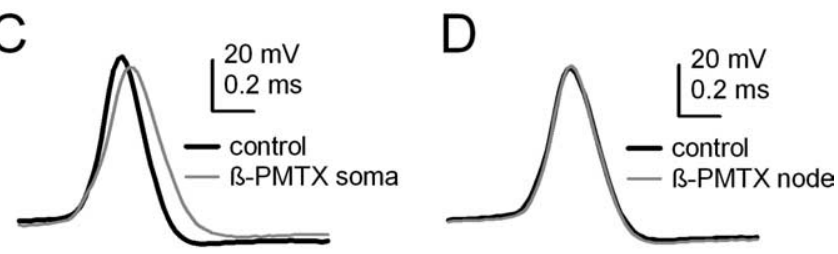

E
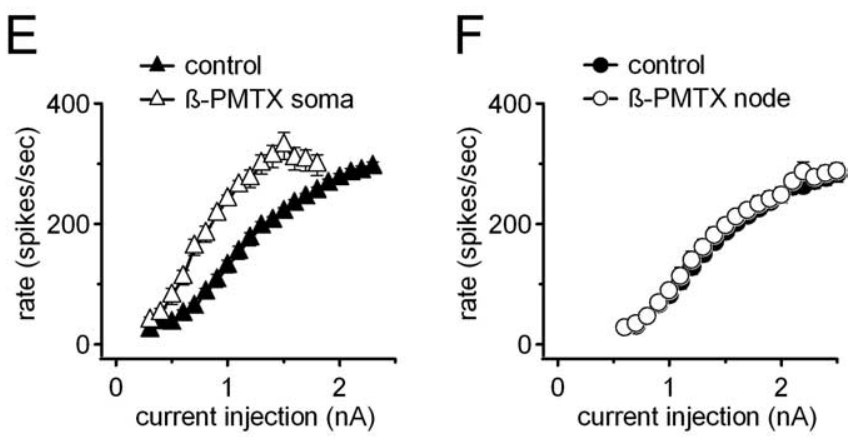

G

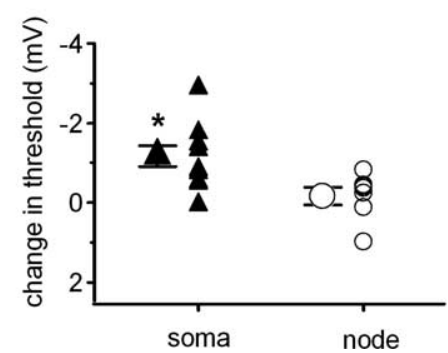

Figure 4. Spiking during application of $\beta$-PMTX to soma and node. $\boldsymbol{A}, \boldsymbol{B}$, Action potentials evoked by $0.7 \mathrm{nA}(\boldsymbol{A})$ or $0.9 \mathrm{nA}(\boldsymbol{B})$ current steps from $-70 \mathrm{mV}$ in control (top) and in somatic (bottom, $\boldsymbol{A}$ ) or nodal (bottom, $\boldsymbol{B}$ ) $\beta$-PMTX. $\boldsymbol{C}, \boldsymbol{D}$, Action potentials for control (black) and $\beta$-PMTX (gray). $\boldsymbol{E}, \boldsymbol{F}$, Input- output curves for $\beta$-PMTX at the soma $(\boldsymbol{E} ; n=16)$ or first node $(\boldsymbol{F}$; $n=7)$. $\mathbf{G}$, Change in threshold for $\beta$-PMTX applied to the soma $(n=10)$ or first node $(n=7)$.

tion in the derivative (Fig. 7D), also evident as a reduction in the first peak of the second derivative $(p<0.001)$ (Fig. 7E). These results are consistent with the idea that the earliest depolarization, i.e., action potential initiation, normally occurs in the initial segment.

Choline block of the initial segment also slightly decreased the gain of input-output curves, reducing the maximal slope from $220 \pm 11$ to $178 \pm 22 \mathrm{~Hz} / \mathrm{nA}(p=0.09)$ (Fig. $7 F)$, and threshold increased from $-44.7 \pm 1.7$ to $-39.6 \pm 1.1 \mathrm{mV}(n=4 ; p=$ $0.014)$. Rheobase was unchanged ( $p=0.2$ ), however, and maximal firing rates still exceeded 100 spikes/s. These data provide evidence that, although the initial segment is required for normal input-output curves, it is not necessary in an absolute sense for 
A

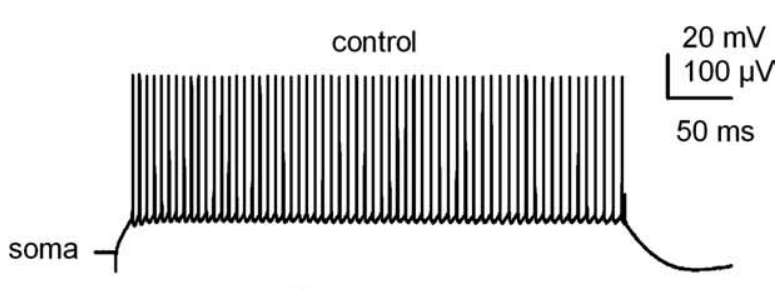

axon
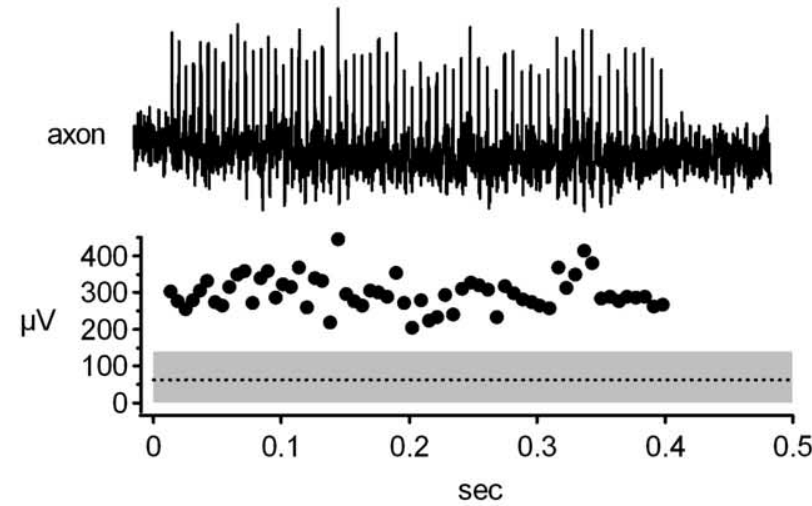

B

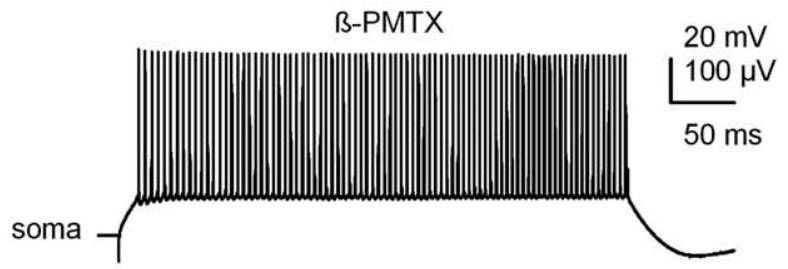

axon
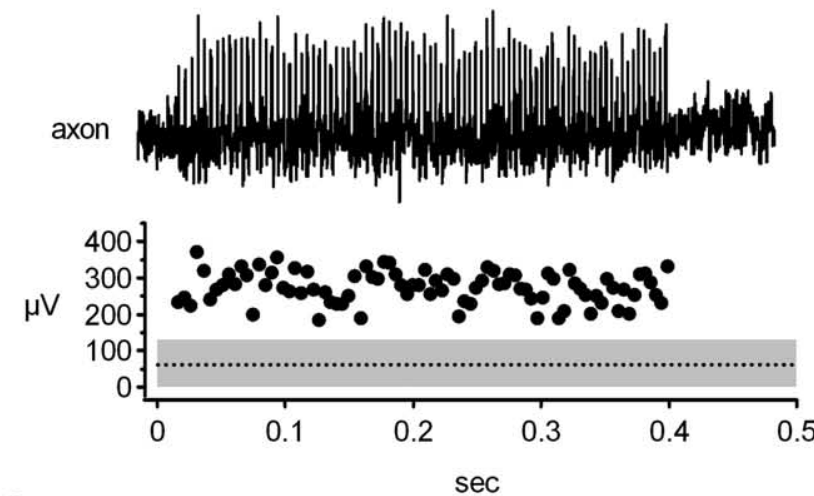

C

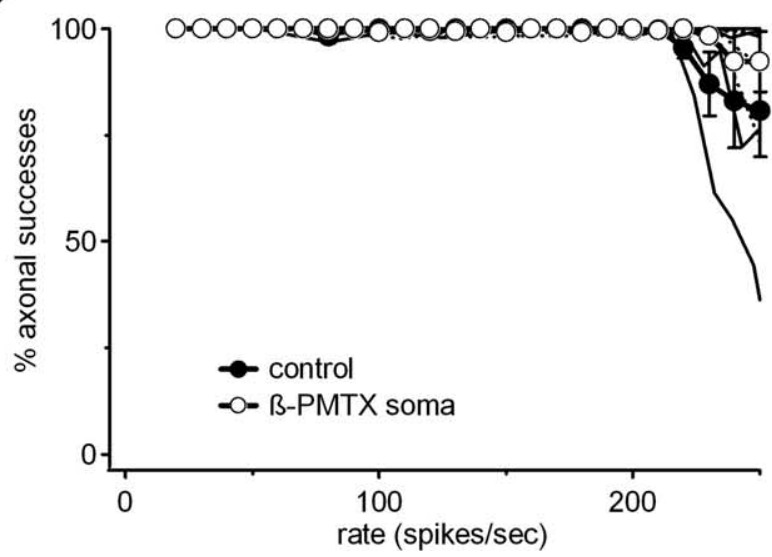

Figure5. Dual somatic and axonal recordings with $\beta$-PMTXapplied to the soma. $A, B$, Somatic (top) and axonal (middle) action potentials evoked from $-70 \mathrm{mV}$ with plots of axonal signal and noise amplitudes in control ( $\boldsymbol{A}$ ) and somatic $\beta$-PMTX (B). All spikes propagated. Axonal recording electrode, $396 \mu \mathrm{m}$ from soma. C, Percentage of propagation successes versus firing rate in control and in somatic $\beta$-PMTX.
A

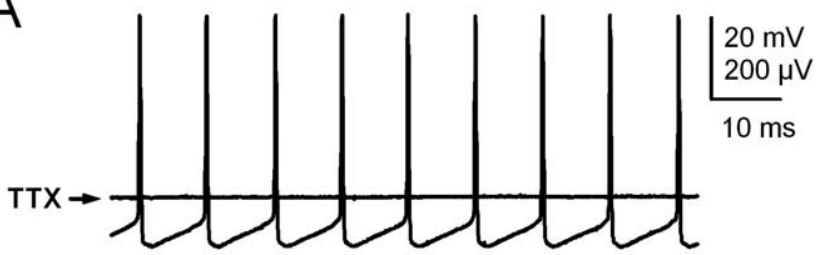

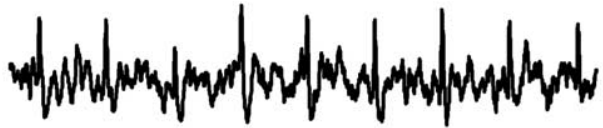

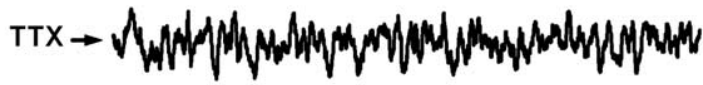

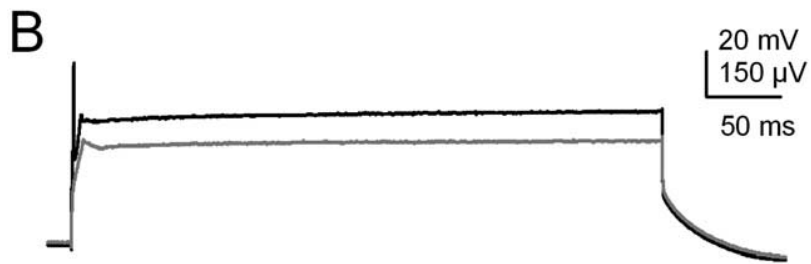

C

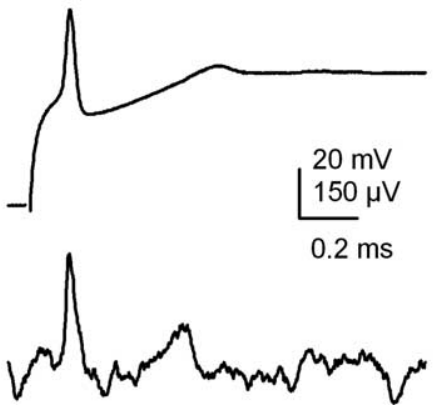

$\mathrm{D}$

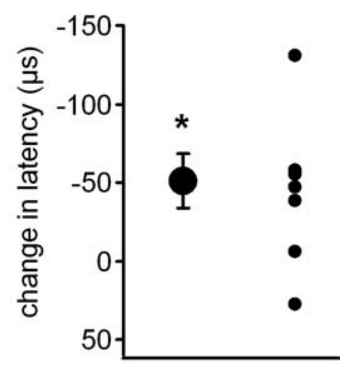

Figure 6. Somatic and axonal spontaneous and evoked responses during somatic TTX application. $\boldsymbol{A}$, Spontaneous activity in soma (top traces) and axon (bottom traces) in control and during somatic TTX. $\boldsymbol{B}$, Evoked responses in soma (top traces) and axon (bottom traces), as in $\boldsymbol{A}$. Suprathreshold response, Black; subthreshold response, gray. $C$, Expanded suprathreshold somatic (top) and axonal (bottom) responses as in $\boldsymbol{B}$. D. Change in spike latency during application of somatic TTX ( $n=8)$. Large symbol, Mean; small symbols, individual values.

the production of action potentials. Instead, channels in the soma, unlike channels in the distal axon, can assume the role of action potential initiation when the initial segment is compromised.

\section{Discussion}

These results indicate that modulation of $\mathrm{Na}$ channels on the soma and initial segment can produce large changes in firing rates and thresholds of action potentials in Purkinje neurons. Additionally, because the initiation site, by reaching threshold, is likely to influence the rate and waveforms of action potentials measured elsewhere in the cell, these data provide direct evidence about the location of action potential initiation. Comparison of $\mathrm{Na}$ channel blockade at the first node and in the perisomatic region suggests that, although $\mathrm{Na}$ channels in the first node facil- 
itate action potential propagation, they do not measurably affect firing rates. In contrast, both upmodulation and downmodulation of perisomatic $\mathrm{Na}$ channels strongly influences the gain of input-output curves. Moreover, the results of choline perfusion indicate that action potential initiation normally occurs within the first $\sim 30 \mu \mathrm{m}$ of the Purkinje cell initial segment.

This conclusion differs from that of Clark et al. (2005). In that study, the latency between somatic and axonal extracellularly recorded membrane currents led to the suggestion that spike initiation occurred in the first node. The interpretation of these data, however, is complicated by at least two factors. First, membrane current is proportional to the first derivative of the membrane voltage, $d V / d t$, for a stationary action potential, but to the second derivative, $d^{2} V / d t^{2}$, for a propagating action potential (Hodgkin and Huxley, 1952). Therefore, when the action potential is stationary, the maximal inward current corresponds to the steepest part of the upstroke of the spike; however, when the action potential is propagating, the maximal inward current corresponds to the inflection preceding the upstroke, underestimating spike latency. In other words, in most regions of the axon, somatic and axonal current signals are not likely to be equivalent measures and cannot be compared directly.

Second, for myelinated axons, the action potential latency is not expected to vary continuously with distance along the axon. Instead, latency versus distance plots follow a step-like function, with latency increases occurring at nodes (Huxley and Stämpfli, 1949; Palmer and Stuart, 2005). As a result, latencies measured anywhere along the myelin between the initial segment and the first node of Ranvier are likely to be constant. Therefore, even if negative latencies were measured just proximal to the node of Ranvier, it would not follow that the spike was initiated at the node rather than at the initial segment.

In fact, the idea of an initiation site close to Purkinje somata is consistent with previous studies of propagation failures, evident as somatic action potentials without axonal spikes, and which occur in Purkinje axons during high-frequency activity (Khaliq and Raman, 2005; Monsivais et al., 2005). Such propagation failures hint that the perisomatic region can be a relatively autonomous spike generator, at least during high-frequency firing, because it is unlikely that action potentials backpropagate to the soma without forward-propagating
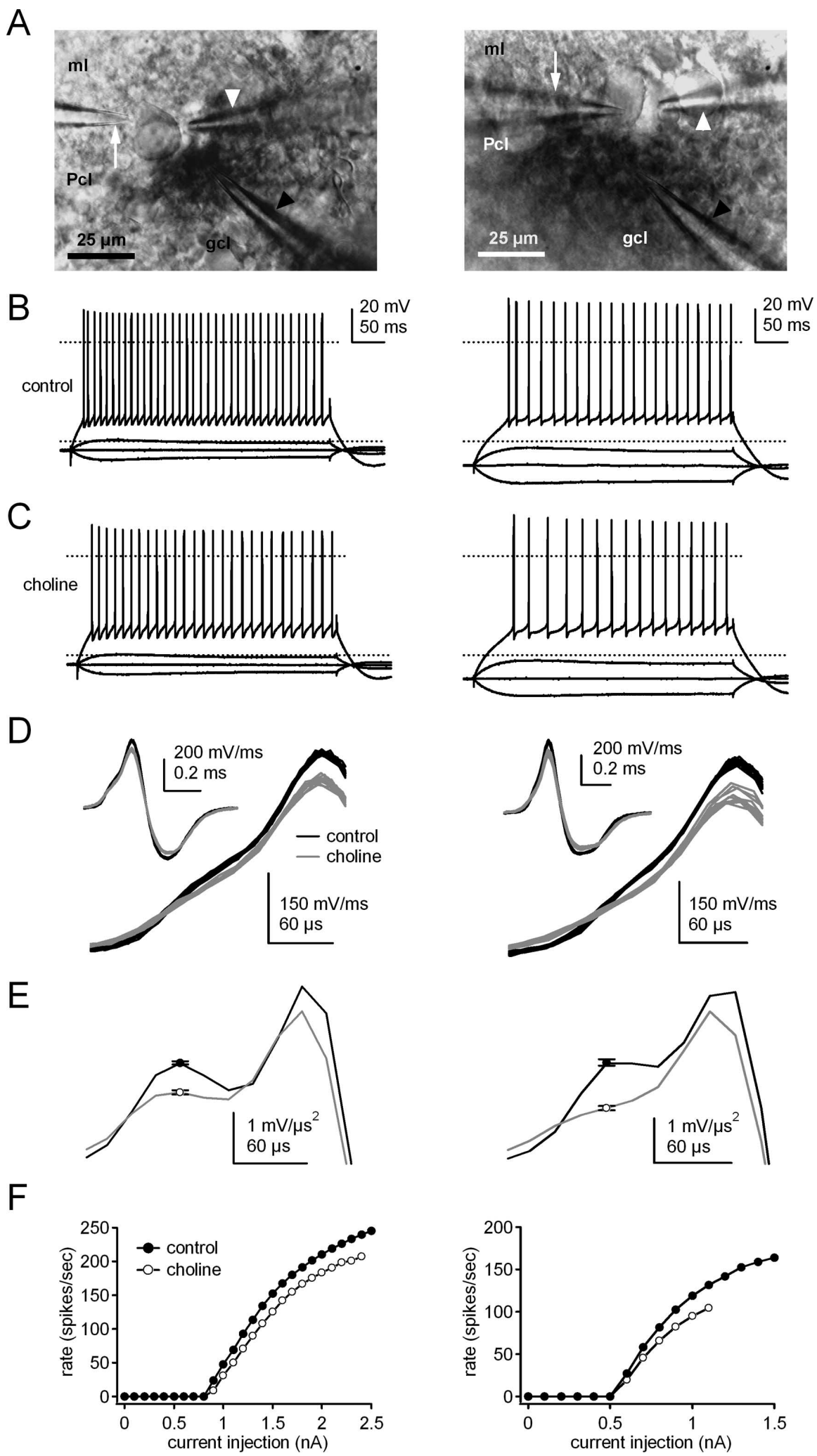

Figure 7. Effect of Na channel blockade at the initial segment on somatic firing. Left and right columns, Data from two Purkinje cells. $\boldsymbol{A}$, Black arrowhead, Puffer pipette applying choline-substituted solution to the initial segment, visualized with fast green (dark areas). White arrowhead, Puffer pipette applying control solution to the soma. White arrow, Recording pipette. Pcl, Purkinje cell; $\mathrm{ml}$, molecular; gcl, granule cell layer. $\boldsymbol{B}, \boldsymbol{C}$, Responses to somatic current steps from $-70 \mathrm{mV}$ in control $(\boldsymbol{B})$ and choline $(\boldsymbol{C})$. Subthreshold current steps, $-0.3,0$, and $0.3 \mathrm{nA}$. Choline decreased firing rates (left, 92 to 70 spikes/s, $1.2 \mathrm{nA}$; right, 58 to 43 spikes $/ \mathrm{s}, 0.7 \mathrm{nA}$ ). Dotted lines, -60 and $0 \mathrm{mV}$. D, Derivatives of spike waveforms in control (black) and choline (gray). Overlay of $10-20$ traces. Insets, Same data on a compressed timescale. $\boldsymbol{E}$, Second derivatives of traces in $\boldsymbol{D}$. F, Input- output curves in control and choline solutions. 
at least some distance along the axon. In fact, failures can be recorded even proximal to the first node (Khaliq and Raman, 2005). Even if initiation were to occur at the first node at low firing rates, receding toward the soma only at high firing rates, this scenario still leads to the conclusion that the most reliable site of initiation in Purkinje cells is perisomatic.

Classical work on motoneurons demonstrated that action potentials are initiated in the initial segment (Coombs et al., 1957a,b), and subsequent studies in both myelinated and unmyelinated central neurons indicate that initiation occurs at or just beyond the initial segment, between 30 and $70 \mu \mathrm{m}$ from the soma (Häusser et al., 1995; Colbert and Johnston, 1996; Williams and Stuart, 1999; Colbert and Pan, 2002; Meeks et al., 2005). These conclusions have been based on either locating the site at which TTX elicits the largest increase in spike threshold (Colbert and Johnston, 1996) or finding the site of negative-latency action potentials in unmyelinated axons (Meeks et al., 2005). Our data identify the relevant part of the axon as slightly more proximal; in Purkinje cells, restricting Na channel block to the first $\sim 30 \mu \mathrm{m}$ of the initial segment with choline reduced or abolished the first phase of the spike waveform derivative while significantly raising threshold and flattening input-output curves.

The total effect of choline on the initial segment was relatively mild, however, resembling that of sub-TTX application to the entire perisomatic region. The present experiments therefore cannot resolve whether $\mathrm{Na}$ channels in the initial segment of Purkinje cells have a unique role beyond contribution of depolarizing drive against a low capacitance. Support for this idea, however, comes from studies of mutant mice lacking ankyrin-G, which usually targets $\mathrm{Na}$ channels to the initial segment and to nodes of Ranvier (Kordeli et al., 1995); Purkinje cells from these mice fire at reduced rates during current injections (Zhou et al., 1998). Moreover, $\mathrm{Na}_{\mathrm{V}} 1.6$ channels, which appear necessary for normal Purkinje cell firing (Raman et al., 1997), are targeted to the initial segment in Purkinje and other neurons (Jenkins and Bennett, 2001; Boiko et al., 2003).

Nevertheless, manipulations that made the initial segment less excitable by $\mathrm{Na}$ channel blockade indicated that the soma, unlike the distal axon, retained the capacity to initiate trains of action potentials. In general, this ease of somatic spiking may reflect a fundamental difference in spike generation in spontaneously firing cells. Specifically, in nonspontaneously active neurons, action potentials are usually initiated by EPSPs, which originate in the dendrite, spread to the soma, and arrive at the axon in which a spike is initiated and backpropagates to the soma and dendrites (Spruston et al., 1995; Colbert and Johnston, 1996). In contrast, the somata of spontaneously firing cells appear to participate more actively in spike initiation. As mentioned, many classes of spontaneously active neurons maintain their characteristic firing patterns in isolated cell body preparations, although they generally retain little if any axon (Raman and Bean, 1997; Raman et al., 2000; Taddese and Bean, 2002; Do and Bean, 2004; Jackson et al., 2004; Puopolo et al., 2005). This persistence of activity despite axonal cleavage must result from factors such as the density and gating properties of somatic channels in spontaneously active cells. For instance, whereas subicular pyramidal cells express three to four Na channels/ $\mu \mathrm{m}^{2}$ (Colbert and Johnston, 1996), Purkinje somata have more than twice the Na channel density, with estimates of 7-10 channels/ $\mu \mathrm{m}^{2}$ (Stuart and Häusser, 1994; Raman and Bean, 1999). In addition, specialized $\mathrm{Na}$ channels in Purkinje somata keep channel availability high and depolarize the membrane at interspike potentials, promoting action potential generation (Raman and Bean, 1999; Khaliq et al., 2003). Somatic
K channels also facilitate spiking, because they deactivate rapidly during repolarization, permitting renewed depolarization soon after each action potential (Raman and Bean, 1999; Southan and Robertson, 2000; Rudy and McBain, 2001).

Whether axonal channels have the same attributes is unknown. Nevertheless, our data suggest that neither the first node nor any part of the axon beyond $\sim 30 \mu \mathrm{m}$ of the initial segment is sufficient to initiate spikes resembling the normal firing patterns of Purkinje cells. This argument is based primarily on the observation that, in the presence of perisomatic TTX, the node and distal axon could not sustain trains of action potentials during steady depolarizations. This result is consistent with work in other preparations showing strong spike frequency adaptation in axons (Bostock, 1995). In motoneurons, this adaptation results from axonal expression of slow outward-rectifier $\mathrm{K}$ channels (Baker et al., 1987); our data suggest that Purkinje axons may share this trait. The failure of Purkinje axons to fire repetitively during steady current injections, despite their ability to produce $>200$ spikes/s when the soma does likewise, supports the classical idea that the first node and distal axon are excellent followers of perisomatic activity. Perhaps not surprisingly, the most overt role of the first node that we could resolve was to improve the fidelity of high-frequency transmission.

Defining how changes in somatic and axonal excitability contribute to setting firing rates allows predictions about which regions on the cell may be good targets for modulating Purkinje cell output. Our data indicate that, excepting a blockade of nodal excitability, which impedes propagation of high-frequency spikes, Purkinje cell firing is relatively resistant to modulation of $\mathrm{Na}$ channels beyond the initial segment. In contrast, perisomatic synaptic inhibition appears well situated to limit firing effectively (Palay and Chan-Palay, 1974; Bobik et al., 2004). Firing is also likely to be sensitive to modulation of perisomatic $\mathrm{Na}$ channels, e.g., by kinases and/or phosphatases (Cantrell and Catterall, 2001 ). Finally, the large effect of perisomatic $\beta$-PMTX on propagating action potentials predicts that changing the amplitude of resurgent $\mathrm{Na}$ current will translate directly into changes in spike output.

\section{References}

Baker M, Bostock H, Grafe P, Martius P (1987) Function and distribution of three types of rectifying channel in rat spinal root myelinated axons. J Physiol (Lond) 383:45-67.

Bobik M, Ellisman MH, Rudy B, Martone ME (2004) Potassium channel subunit Kv3.2 and the water channel aquaporin-4 are selectively localized to cerebellar pinceau. Brain Res 1026:168-178.

Boiko T, Van Wart A, Caldwell JH, Levinson SR, Trimmer JS, Matthews G (2003) Functional specialization of the axon initial segment by isoformspecific sodium channel targeting. J Neurosci 23:2306-2313.

Bostock H (1995) Mechanisms of accommodation and adaptation in myelinated axons. In: The axon (Waxman SG, Stys PK, Kocsis JD, eds), pp 311-327. Oxford: Oxford UP.

Cantrell AR, Catterall WA (2001) Neuromodulation of $\mathrm{Na}^{+}$channels: an unexpected form of cellular plasticity. Nat Rev Neurosci 2:397-407.

Clark BA, Monsivais P, Branco T, London M, Häusser M (2005) The site of action potential initiation in cerebellar Purkinje neurons. Nat Neurosci 8:137-139.

Colbert CM, Johnston D (1996) Axonal action-potential initiation and $\mathrm{Na}^{+}$channel densities in the soma and axon initial segment of subicular pyramidal neurons. J Neurosci 16:6676-6686.

Colbert CM, Pan E (2002) Ion channel properties underlying axonal action potential initiation in pyramidal neurons. Nat Neurosci 5:533-538.

Coombs JS, Curtis DR, Eccles JC (1957a) The interpretation of spike potentials of motoneurones. J Physiol (Lond) 139:198-231.

Coombs JS, Curtis DR, Eccles JC (1957b) The generation of impulses in motoneurones. J Physiol (Lond) 139:232-249. 
Do MT, Bean BP (2004) Sodium currents in subthalamic nucleus neurons from Nav1.6-null mice. J Neurophysiol 92:726-733.

Gianola S, Rossi F (2004) GAP-43 overexpression in adult mouse Purkinje cells overrides myelin-derived inhibition of neurite growth. Eur J Neurosci 19:819-830

Grieco TM, Raman IM (2004) Production of resurgent current in NaV1.6null Purkinje neurons by slowing sodium channel inactivation with $\beta$-pompilidotoxin. J Neurosci 24:35-42.

Häusser M, Clark BA (1997) Tonic synaptic inhibition modulates neuronal output pattern and spatiotemporal synaptic integration. Neuron 19:665-678.

Häusser M, Stuart G, Racca C, Sakmann B (1995) Axonal initiation and active dendritic propagation of action potentials in substantia nigra neurons. Neuron 15:637-647.

Hodgkin AL, Huxley AF (1952) A quantitative description of membrane current and its application to conduction and excitation in nerve. J Physiol (Lond) 117:500-544.

Huxley AF, Stämpfli R (1949) Evidence for saltatory conduction in peripheral saltatory nerve fibres. J Physiol (Lond) 108:315-339.

Jackson AC, Yao GL, Bean BP (2004) Mechanism of spontaneous firing in dorsomedial suprachiasmatic nucleus neurons. J Neurosci 24:7985-7998.

Jenkins SM, Bennett V (2001) Ankyrin-G coordinates assembly of the spectrin-based membrane skeleton, voltage-gated sodium channels, and L1 CAMs at Purkinje neuron initial segments. J Cell Biol 155:739-746.

Khaliq ZM, Raman IM (2005) Axonal propagation of simple and complex spikes in cerebellar Purkinje neurons. J Neurosci 25:454-463.

Khaliq ZM, Gouwens NW, Raman IM (2003) The contribution of resurgent sodium current to high-frequency firing in Purkinje neurons: an experimental and modeling study. J Neurosci 23:4899-4912.

Kinoshita E, Maejima H, Yamaoka K, Konno K, Kawai N, Shimizu E, Yokote S, Nakayama H, Seyama I (2001) Novel wasp toxin discriminates between neuronal and cardiac sodium channels. Mol Pharmacol 59:1457-1463.

Kordeli E, Lambert S, Bennett V (1995) AnkyrinG. A new ankyrin gene with neural-specific isoforms localized at the axonal initial segment and node of Ranvier. J Biol Chem 270:2352-2359.

Llinás R, Sugimori M (1980) Electrophysiological properties of in vitro Purkinje cell dendrites in mammalian cerebellar slices. J Physiol (Lond) 305:197-213.

Meeks JP, Jiang X, Mennerick S (2005) Action potential fidelity during nor$\mathrm{mal}$ and epileptiform activity in paired soma-axon recordings from rat hippocampus. J Physiol (Lond) 566:425-441.

Monsivais P, Clark BA, Roth A, Häusser M (2005) Determinants of action potential propagation in cerebellar Purkinje cell axons. J Neurosci 25:464-472.

Moore JW, Westerfield M (1983) Action potential propagation and threshold parameters in inhomogeneous regions of squid axons. J Physiol (Lond) 336:285-300.

Moore JW, Stockbridge N, Westerfield M (1983) On the site of impulse initiation in a neurone. J Physiol (Lond) 336:301-311.

Nam SC, Hockberger PE (1997) Analysis of spontaneous electrical activity in cerebellar Purkinje cells acutely isolated from postnatal rats. J Neurobiol 33:18-32.

Palay SL, Chan-Palay V (1974) Cerebellar cortex. Cytology and organization. Berlin: Springer.

Palmer LM, Stuart GJ (2005) Site of action potential initiation in cortical layer 5 pyramidal neurons. Soc Neurosci Abstr 31:728.18.

Puopolo M, Bean BP, Raviola E (2005) Spontaneous activity of isolated dopaminergic periglomerular cells of the main olfactory bulb. J Neurophysiol 94:3618-3627.

Raman IM, Bean BP (1997) Resurgent sodium current and action potential formation in dissociated cerebellar Purkinje neurons. J Neurosci 17:4517-4526.

Raman IM, Bean BP (1999) Ionic currents underlying spontaneous action potentials in isolated cerebellar Purkinje neurons. J Neurosci 19:1663-1674.

Raman IM, Bean BP (2001) Inactivation and recovery of sodium currents in cerebellar Purkinje neurons: evidence for two mechanisms. Biophys J 80:729-737.

Raman IM, Sprunger LK, Meisler MH, Bean BP (1997) Altered subthreshold sodium currents and disrupted firing patterns in Purkinje neurons of Scn8a mutant mice. Neuron 19:881-891.

Raman IM, Gustafson AE, Padgett D (2000) Ionic currents and spontaneous firing in neurons isolated from the cerebellar nuclei. J Neurosci 20:9004-9016.

Rudy B, McBain CJ (2001) Kv3 channels: voltage-gated $\mathrm{K}^{+}$channels designed for high-frequency repetitive firing. Trends Neurosci 24:517-526.

Sekirnjak C, Vissel B, Bollinger J, Faulstich M, du Lac S (2003) Purkinje cell synapses target physiologically unique brainstem neurons. J Neurosci 23:6392-6398.

Southan AP, Robertson B (2000) Electrophysiological characterization of voltage-gated $\mathrm{K}^{+}$currents in cerebellar basket and Purkinje cells: Kvl and Kv3 channel subfamilies are present in basket cell nerve terminals. J Neurosci 20:114-122.

Spruston N, Schiller Y, Stuart G, Sakmann B (1995) Activity-dependent action potential invasion and calcium influx into hippocampal CA1 dendrites. Science 268:297-300.

Stuart G, Häusser M (1994) Initiation and spread of sodium action potentials in cerebellar Purkinje cells. Neuron 13:703-712.

Swensen AM, Bean BP (2005) Robustness of burst firing in dissociated Purkinje neurons with acute or long-term reductions in sodium conductance. J Neurosci 25:3509-3520.

Taddese A, Bean BP (2002) Subthreshold sodium current from rapidly inactivating sodium channels drives spontaneous firing of tuberomammillary neurons. Neuron 33:587-600.

Williams SR, Stuart GJ (1999) Mechanisms and consequences of action potential burst firing in rat neocortical pyramidal neurons. J Physiol (Lond) 521:467-482.

Zhou D, Lambert S, Malen PL, Carpenter S, Boland LM, Bennett V (1998) Ankyring is required for clustering of voltage-gated Na channels at axon initial segments and for normal action potential firing. J Cell Biol 143: 1295-1304. 